\title{
Expression of P-glycoprotein in hepatocellular carcinoma: a potential marker of prognosis
}

\author{
Y Soini, N Virkajärvi, H Raunio, P Pääkkö
}

\begin{abstract}
Aims-(1) To investigate the immunohistochemical expression of the multidrug resistance gene (MDR1) product P-glycoprotein in histological samples from 31 hepatocellular carcinomas (HCCs); and (2) to correlate the results with cell proliferation, p53 expression, the disease-free interval, and cumulative patient survival. Methods-C219 (a monoclonal antibody), CM-1 (a polyclonal rabbit anti-human antibody) and PC10 (a monoclonal mouse anti-human antibody) were used to detect expression of P-glycoprotein, p53 and proliferating cell nuclear antigen (PCNA), respectively, by means of the avidin-biotin peroxidase method.
\end{abstract}

Results-Membrane bound positivity for P-glycoprotein was observed in $20(65 \%)$ of the 31 HCCs. Cytoplasmic globular positivity was also seen in some cases. There were no significant associations between expression of $\mathbf{P}$-glycoprotein and cell proliferation (determined by PCNA immunoexpression and the mitotic count), or p53 expression. Patients with P-glycoprotein positive tumours had a shorter disease-free interval than those with P-glycoprotein negative tumours, and also had a shorter survival time. There was no difference in survival between $\mathbf{P}$-glycoprotein positive patients who had or had not received chemotherapy, suggesting that chemotherapy (mainly mitomycin-C) did not affect survival in these patients.

Conclusions-Expression of P-glycoprotein in HCCs is associated with a shorter disease-free interval and shorter survival time. As expression of $\mathbf{P}$-glycoprotein was not associated with cell proliferation or expression of p53, its effect on disease progression and survival seems to be independent of these factors.

( Clin Pathol 1996;49:470-473)

Keywords: MDR, liver, hepatocellular carcinoma, p53, PCNA.

P-glycoprotein is a $\mathbf{1 7 0}$ kilodalton, membrane bound glycoprotein encoded by the multidrug resistance (MDR 1) gene ${ }^{12}$ and functions as an ATP dependent pump propelling drugs and cytostatics out of the cell cytoplasm. Because of its involvement in drug resistance, the expression of P-glycoprotein has been studied in several different neoplasms and increased $\mathrm{P}$-glycoprotein expression has been found in several epithelial tumours, such as those of the colon and breast. ${ }^{3-6}$ In breast carcinomas expression of P-glycoprotein has been associated with $\mathrm{p} 53$ expression and cell proliferation, as evaluated by the Ki67 index. ${ }^{5}$ P-glycoprotein expression has also been associated with a shorter disease-free interval in carcinomas of the breast, colon and kidney. ${ }^{48}$

Expression of P-glycoprotein has been studied previously in liver cells and in hepatocellular carcinomas (HCCs). In non-neoplastic liver $P$-glycoprotein is expressed in the biliary canalicular pole of hepatocytes ${ }^{3}$ and in epithelial cells lining the biliary ducts; $60-70 \%$ of HCCs are P-glycoprotein positive. ${ }^{3} 9$ Activation of the MDR1 gene in hepatic tissues has been studied extensively in animal models; several rodent hepatocarcinogenesis models show that enhanced MDR1 expression is associated with the later stages of carcinogenesis. ${ }^{10}$

In this study we investigated P-glycoprotein expression in 31 patients with HCC. The aim of the investigation was to compare P-glycoprotein expression with the disease-free interval, cumulative survival and other clinical parameters.

\section{Methods}

Sections from 31 HCCs (from 13 men and 18 women) resected between 1983 and 1993 were retrieved from the files of the Department of Pathology, Oulu University Hospital. All of the material had been fixed in $10 \%$ neutral formalin and embedded in paraffin wax. In all cases the diagnosis had been based on conventional light microscopy, according to the criteria of the World Health Organisation. ${ }^{11}$ Table 1 shows the histological type of the tumours, their grade and TNM status. The grade of the tumours was determined as suggested by Edmonson and Steiner ${ }^{12}$ and the stage as recommended by Spiessl et al. ${ }^{13}$ The case histories of all the patients were reviewed and the pertinent clinical data, including survival, stage, ${ }^{13}$ age, and sex of each patient were collated. Six of the patients were alive, five had died of disease other than HCC or during surgery. Fourteen patients received chemotherapy following surgery: all initially received mitomycin-C; two patients were subsequently treated with epirubicin and one with doxorubicin. One patient had a history of viral hepatitis, two patients had chronic aggressive hepatitis, one had primary biliary cirrhosis, and seven had cirrhosis. Mean (SD) age was 60.9 (15.5) years and the mean (SD) tumour size was 10.8 $(7.2) \mathrm{cm}$. 
Table 1 Immunohistochemical expression of $P$-glycoprotein in relation to histological type, tumour grade and stage, PCNA, immunohistochemical expression of $p 53$, and patient survival

\begin{tabular}{|c|c|c|c|c|c|c|}
\hline $\begin{array}{l}\text { Histological } \\
\text { type }\end{array}$ & $P$-glycoprotein & Grade & PCNA (\%) & $\begin{array}{l}\text { Tumour } \\
\text { stage }^{\star}\end{array}$ & $p 53$ & $\begin{array}{l}\text { Survival } \\
\text { (months) }\end{array}$ \\
\hline Compact & ++ & III & 10 & T2NOMO & - & $0.2 \ddagger$ \\
\hline Trabecular & + & III & 30 & T2NOMO & - & $18^{\star \star}$ \\
\hline Compact & + & III & 40 & T2NOM0 & - & $12 \ddagger$ \\
\hline Compact & ++ & II & 40 & T3N0M0 & - & $8 \dagger$ \\
\hline Trabecular & ++ & II & 40 & T3NOMO & - & $25 t$ \\
\hline Trabecular & +++ & II & 55 & T2N0M0 & - & $54 \delta$ \\
\hline Compact & + & III & 70 & T2NOM0 & - & $36 \S$ \\
\hline Compact & + & III & 90 & T3NOMO & ++ & $6+$ \\
\hline Compact & + & II & 5 & T3NOMO & - & $2 \dagger$ \\
\hline Trabecular & + & II & 5 & T3N0M0 & - & $1 \dagger$ \\
\hline Trabecular & +++ & II & 5 & T2NOMO & - & $36 \ddagger$ \\
\hline Compact & + & III & 70 & T3NOMO & - & $5 t$ \\
\hline Trabecular & +++ & II & 30 & T3NOMO & + & $0.1 \neq$ \\
\hline Fibrolamellar & $r+$ & III & 95 & T2NOMO & + & $2 t$ \\
\hline Compact & + & III & 20 & T2NOMO & - & $108^{\star \star}$ \\
\hline Compact & + & II & 40 & T3NOMO & - & $15 \dagger$ \\
\hline Compact & ++ & II & 70 & T3NOMO & - & $3 t$ \\
\hline Compact & +++ & II & 5 & T3NOMO & - & $6 \star \star \star$ \\
\hline Acinar & + & II & 65 & T2NOMO & - & $5 t$ \\
\hline Trabecular & +++ & $\mathrm{I}$ & 10 & T3N0M0 & - & $102 t$ \\
\hline Trabecular & - & III & 20 & T2NOMO & - & $24^{\star \star}$ \\
\hline Compact & - & III & 95 & T2NOMO & + & $36 \S$ \\
\hline Compact & - & III & 5 & T2NOMO & - & $48 \delta^{\circ}$ \\
\hline Acinar & _- & II & 20 & T1NOMO & _- & $55 \ddagger$ \\
\hline Trabecular & - & III & 30 & T3NOMO & - & $36 \delta^{\circ}$ \\
\hline Compact & - & III & 70 & T2NOMO & + & $4 \dagger$ \\
\hline Compact & - & II & 70 & T3N0M0 & + & $2 t$ \\
\hline Compact & - & II & 5 & T3N0M0 & - & $34+$ \\
\hline Compact & - & III & 95 & T2NOMO & +++ & 1085 \\
\hline Compact & - & III & 10 & T2N0M0 & - & $60^{\star \star}$ \\
\hline Trabecular & - & I & 30 & T2N0M0 & - & $10 \dagger$ \\
\hline
\end{tabular}

*At the time of operation.

Evaluation of P-glycoprotein and $\mathrm{p} 53$ immunoexpression: $-=$ negative; $+=\leqslant 10 \%$ tumour cells positive; $++=\leqslant 30 \%$ tumour cells positive; $+++=>30 \%$ tumour cells positive. †Died of disease.

$\ddagger$ Died during surgery or of other disease.

oStill alive.

$\star \star$ Lost to follow up at this stage.

IMMUNOHISTOCHEMISTRY

Sections, $5 \mu \mathrm{m}$ thick, were cut from the specimens and mounted on poly-l-lysine coated glass slides (Sigma, St Louis, Missouri, USA), air dried overnight and stained within a few days. Slides were dewaxed in xylene and rehydrated through graded alcohol. Endogenous peroxidase activity was blocked by immersing the slides in $0.1 \%$ hydrogen peroxide in absolute methanol for 20 minutes. Nonspecific binding was blocked by incubating the

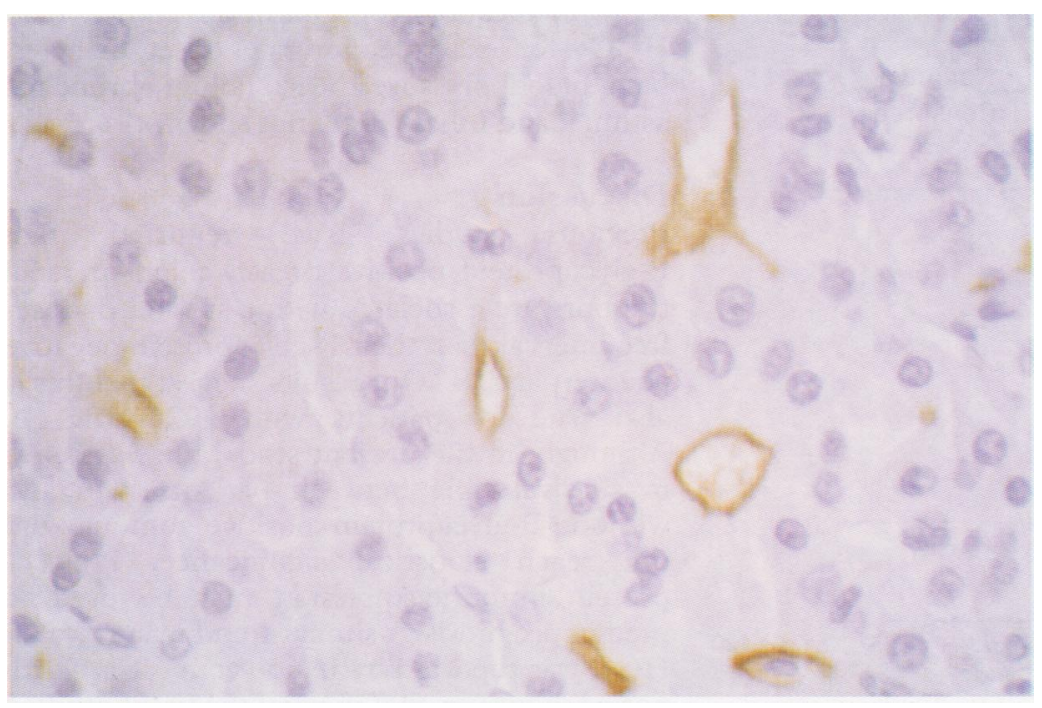

Figure $1 P$-glycoprotein immunostaining localised to the cell membrane (immunoperoxidase, $\times 200$ ). slides in $20 \%$ fetal calf serum in phosphate buffered saline (PBS) for 20 minutes.

Sections were pretreated in a microwave oven in $10 \mathrm{mM}$ citric acid monohydrate, $\mathrm{pH}$ 6.0, for three minutes and were then incubated with the primary monoclonal antibody (C219; Signet Laboratories, Dedham, Massachusetts, USA) (diluted 1 in 20) directed against P-glycoprotein for three hours. The biotinylated secondary anti-mouse antibody (Dako, Glostrup, Denmark) (diluted 1 in 300) was applied, followed by the avidin-biotin peroxidase complex (Dako). Normal liver served as an internal positive control.

To detect $\mathrm{p} 53$ expression, sections were first incubated overnight at $4^{\circ} \mathrm{C}$ with a polyclonal rabbit anti-human p53 antibody (CM-1; Novocastra Laboratories, Newcastle upon Tyne, UK) diluted 1 in $1000 .{ }^{14} \mathrm{~A}$ biotinylated anti-rabbit immunoglobulin (diluted 1 in 100; Dako) and the avidin-biotin peroxidase complex were then added. Sections from a lung carcinoma previously shown to be strongly positive for p53 served as a positive control. ${ }^{14}$

A mouse monoclonal $\operatorname{IgG}_{2 a}$ primary antibody (PC10; Dako) was used to detect proliferating cell nuclear antigen (PCNA). The sections were incubated with the primary antibody (diluted 1 in 50) for one hour, followed by a secondary rabbit anti-mouse antibody (diluted 1 in 200) (Dako) and the avidin-biotin peroxidase complex. A lymph node with follicular hyperplasia served as positive control.

In all cases sections were rinsed stringently, with several changes of PBS between each stage. Diaminobenzidine was used as the chromogen. Sections were were lightly counterstained with haematoxylin and mounted with Eukitt (Kindler, Freiburg, Germany). For negative controls non-immune mouse or rabbit serum replaced the primary antibodies in all cases.

Expression of P-glycoprotein and p53 was scored as follows: $-=$ negative; $+=\leqslant 10 \%$ tumour cells positive; $++=\leqslant 30 \%$ tumour cells positive; $+++=>30 \%$ tumour cells positive. In the case of PCNA, the percentage of positively stained cells was evaluated in each section. P-glycoprotein immunostaining was mainly localised to the membrane, although cytoplasmic staining was seen in some sections. PNCA and p53 immunoreactivity was nuclear. Cell proliferation was also assessed by counting the number of mitotic figures per 10 high power fields.

\section{STATISTICAL ANALYSIS}

Comparisons between groups were made using the two-tailed Student's $t$ test. The significance of associations was determined using Fisher's exact probability test and correlation analysis. Survival data were analysed using the KaplanMeyer method. The difference between survival in different groups was analysed using the $\log$ rank test. Probability values of less than 0.05 were considered significant.

\section{Results}

P-glycoprotein was expressed in 20 (65\%) of the $31 \mathrm{HCCs}$. Immunoreactivity was mainly confined to the cell membrane, but in some 


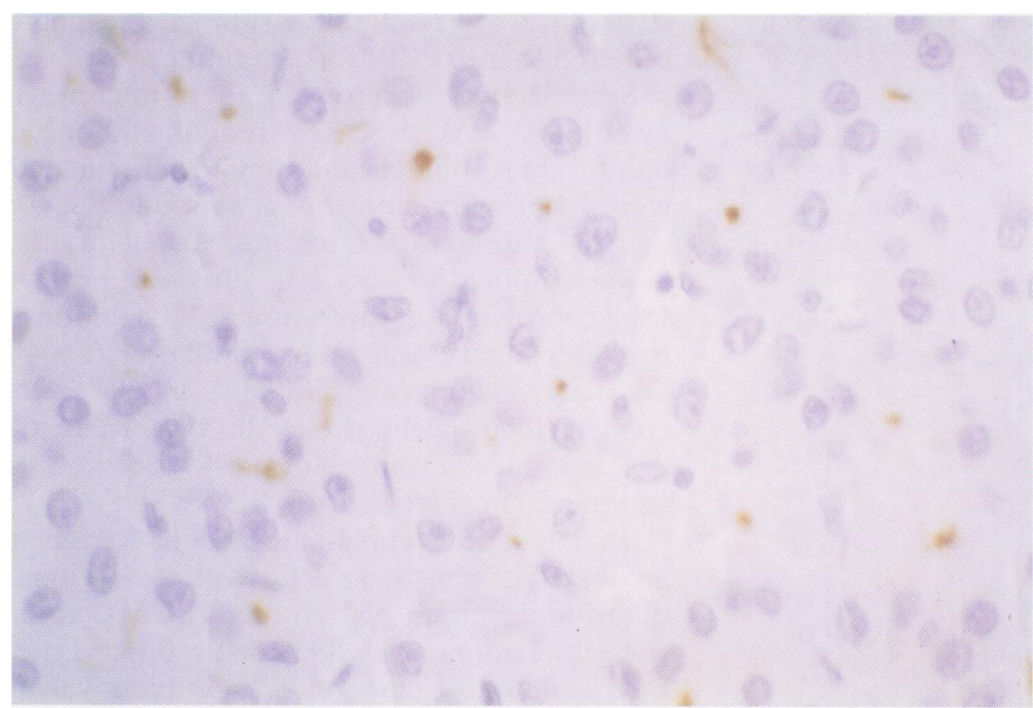

Figure 2 Photomicrograph showing globular intracytoplasmic immunostaining (immunoperoxidase, $\times 200$ ).

cases globular intracytoplasmic staining was also seen (figs 1 and 2). Adjacent normal liver tissue was also stained positively. Some of the

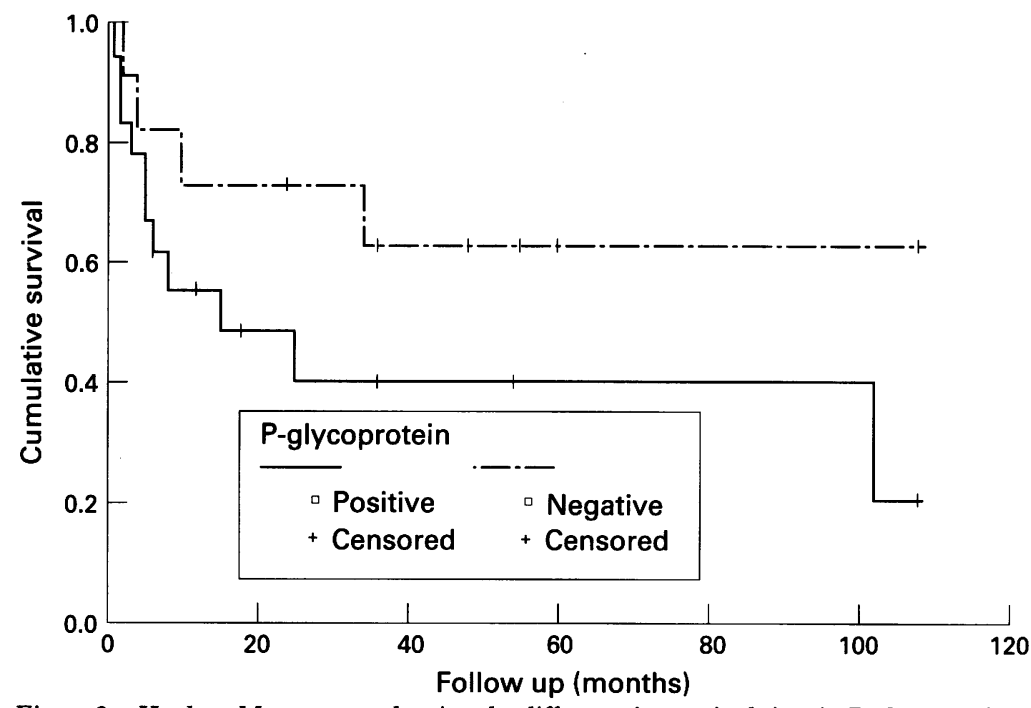

Figure 3 Kaplan-Meyer curve showing the difference in survival time in P-glycoprotein positive and negative tumours.

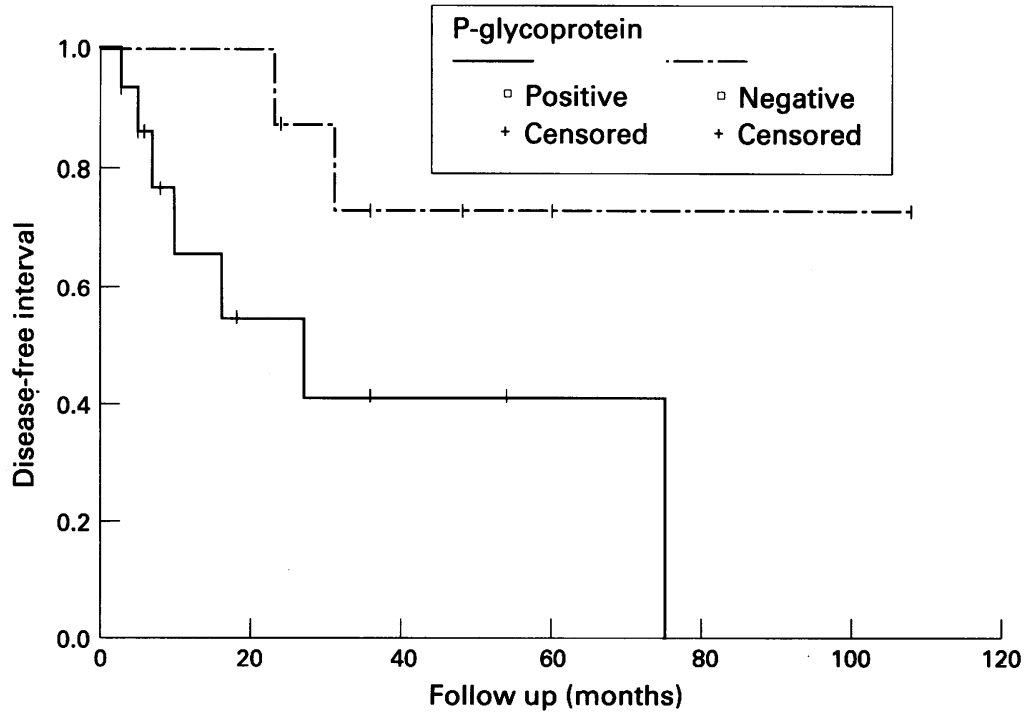

Figure 4 Kaplan-Meyer curve showing the difference in the disease-free interval in $P$-glycoprotein positive and negative tumours. Patients with P-glycoprotein positive tumours had a significantly shorter disease-free interval ( $p<0.05$, log rank test). proliferating bile ductules were P-glycoprotein positive at their luminal surface.

There was no difference in the immunostaining pattern observed in the different HCC histological types. Tumour grade or stage was not significantly associated with positive immunostaining, although tumours of lower grade $(p=0.19)$ and higher stage $(p=0.13$, Fisher's exact test) tended to be more heavily stained. P-glycoprotein expression was not significantly associated with cell proliferation, as measured by positive PCNA immunoexpression ( $\mathrm{p}=0.92$, two-tailed $t$ test) and mitotic counts ( $\mathrm{p}=0.96$, two-tailed $t$ test). Expression of $\mathrm{P}$-glycoprotein in $\mathrm{p} 53$ positive and negative tumours was not significantly different ( $p=$ 0.18 , Fisher's exact test). Patients with P-glycoprotein positive tumours had a shorter survival time (mean (SD) 47.0 (12.0) months, 95\% confidence interval (CI) 23.4-70.6 months) than those with P-glycoprotein negative tumours (72.3 (14.3) months, 95\% CI 44.3-100.3 months) (fig 3). The difference in survival time between these two groups was not statistically significant $(p=0.18, \log$ rank test). The disease-free interval (no evidence of recurrence either clinically or on laboratory investigation) was significantly shorter in patients with P-glycoprotein positive (38.5 (10.9) months, 95\% CI 17.1-60.0 months) than in those with negative tumours (86.2 (13.3) months, 95\% CI 60.1-112.2 months) (p < $0.05, \log$ rank test) (fig 4 ). The survival time of patients with $\mathrm{P}$-glycoprotein positive tumours who received chemotherapy (41.0 (15.3) months, 95\% CI 11.1-70.9 months) did not differ significantly from that of all patients studied (60.0 (10.5) months, 95\% CI 39.380.6 months) ( $p=0.26, \log$ rank test) or from patients with P-glycoprotein positive HCCs who did not receive chemotherapy (28.3 (8.1) months, 95\% CI 12.4-44.1 months) ( $\mathrm{p}=$ 0.95).

Seven patients also had liver cirrhosis, of whom five had P-glycoprotein positive tumours $(p=0.49$, Fisher's exact test). There was no statistically significant association between P-glycoprotein expression and long term medication for conditions other than HCC-for example, for late onset diabetes, high blood pressure, heart failure, bronchial asthma, and others (data not shown).

\section{Discussion}

Previous studies have reported that P-glycoprotein positive breast, colon or renal tumours are associated with a shorter diseasefree interval than their P-glycoprotein negative counterparts. ${ }^{48}$ Our results suggest that this is also true for patients with HCC (fig 3). Although, in the present study, the difference in survival time between patients with and without P-glycoprotein positive tumours did not reach statistical significance, P-glycoprotein immunoexpression may be used to predict prognosis. A similar trend in survival in HCC was reported by Itsubo et al. ${ }^{9}$ It is worth noting, however, that most of the tissue studied by Itsubo et al was obtained at necropsy, whereas in the present study all tissue was 
obtained at surgery from patients who had not undergone preoperative chemotherapy. In some cases chemotherapy may induce P-glycoprotein expression, ${ }^{2}$ which may then have an adverse effect on prognosis.

Twelve patients underwent postoperative chemotherapy. All patients received mitomycin-C; two patients subsequently received epirubicin and one doxorubicin. To test whether chemotherapy influenced postoperative survival, we compared P-glycoprotein expression in patients who did and did not undergo chemotherapy. No difference in the survival time was found, suggesting that chemotherapy did not affect prognosis in patients with P-glycoprotein positive tumours. The reason for this may be because mitomycin- $\mathrm{C}$ was the main chemotherapeutic agent used in the present study and has been found to be insensitive to drug resistance induced by MDR1 in vitro. ${ }^{15}$

P-glycoprotein immunostaining was mainly confined to the cell membrane in HCCs, a pattern which was also seen in the adjacent non-neoplastic liver cells. Intracellular globular immunostaining was observed in some cases, and its perinuclear location suggested that P-glycoprotein was present in the Golgi apparatus, confirming previous electron microscopy studies. ${ }^{1}$

Chin et $a l^{16}$ reported that mutant p53 can activate the MDR1 promoter and Charpin et $a \hat{f}$ found that expression of $\mathrm{P}$-glycoprotein was associated with $\mathrm{p} 53$ expression and with a high proliferation rate in breast cancer. In contrast, however, De Angelis et al $^{17}$ found no association between expression of p53 and P-glycoprotein in colorectal carcinomas. This was also the case in the present study, suggesting that expression of $\mathrm{p} 53$ and cell proliferation have no effect on P-glycoprotein expression in HCC.

In conclusion, expression of P-glycoprotein in HCCs is associated with a shorter diseasefree interval and shorter survival time. As expression of P-glycoprotein was not associated with cell proliferation or expression of p53, its effect on disease progression and survival seems to be independent of these factors.
We are grateful to Ms Mirja Vahera and Ms Marja Tolppanen for their technical assistance. This study was supported by the Finnish Cancer Societies and the Finnish Anti-Tuberculosis Association.

1 Dietel $M$. What's new in cytostatic drug resistance and pathology. Pathol Res Pract 1991;187:892-905.

2 Gottesman MM. How cancer cells evade chemotherapy: Sixteenth Richard and Hinda Rosenthal Foundation Sixteenth Richard and Hinda Rosenthare. Cancer Res 1993;53:747-54.

3 Cordon-Cardo C, O'Brien JP, Boccia J, Casals D, Bertino JR, Melamed MR. Expression of the multidrug resistance gene product (P-glycoprotein) in human normal and tumor tissues. F Histochem Cytochem 1990;38:1277-87.

4 Verrelle P, Meissonnier F, FonckY, Feillel V, Dionet C, Kwiatkowski F, et al. Clinical relevance of immunohistochemical detection of multidrug resistance P-glycoprotein in breast carcinoma. $\mathcal{F}$ Natl Cancer Inst 1991;83:111-16.

5 Charpin C, Vielh P, Duffaud F, Devictor B, Andrac L, Lavaut MN, et al. Quantitative immunocytochemical assays of P-glycoprotein in breast carcinoma: correlation to messenger RNA expression and to immunohistochemical prognostic indicators. $f$ Natl Cancer Inst 1994; cal prognostic

6 Kramer R, Weber TK, Morse B, Arceci R, Staniunas R, Steele G, Summerhayes IC. Constitutive expression of multidrug resistance in human colorectal tumours and cel lines. $\mathrm{Br} \mathcal{F}$ Cancer 1993;67:959-68.

7 Sinicrope FA, Hart J, Brasitus TA, Michelassi F, Lee JJ, Safa AR. Relationship of P-glycoprotein and carcinoembryonic antigen expression in human colon carcinoma to local invasion, DNA ploidy, and disease relapse. Cancer invasion, DNA ploi.

8 Duensing S, Dallmann I, Grosse J, Buer J, Lopez Hanninen $\mathrm{E}$, Deckert $\mathrm{M}$, et al. Immunocytochemical detection of P-glycoprotein: initial expression correlates with survival in renal cell carcinoma patients. Oncology 1994;51:30913.

9 Itsubo $M$, Ishikawa T, Toda G, Tanaka M. Immunohistochemical study of expression and cellular localization of the multidrug resistance gene product P-glycoprotein in primary liver carcinoma. Cancer 1994;73:298-303.

10 Silverman JA, Thorgeirsson SS. Regulation and function of the multidrug resistance genes in liver. In: Boyer JD, Ockner RK, eds. Progress in liver sisease. Vol XII. Philadelphia: ner RK, eds. Progress in liver

11 Gibson JB, Sobin LH. Histological typing of tumours of the liver, biliary tract and pancreas. International histological classification of tumours. No 20. Geneva: World Health Organization, 1978.

12 Edmondson HA, Steiner PE. Primary carcinoma of the liver: a study of 100 cases among 48900 necropsies. Cancer 1954;7:462-503.

13 Spiessl B, Beahrs OH, Hermanek P, Hutter RVP, Scheibe O, Sobin LH, Wagner G. TNM Atlas. Illustrated guide to the TNM/pTNM classification of malignant tumours. 3rd edn. Berlin: Springer Verlag, 1992.

14 Soini Y, Pääkkö P, Nuorva K, Kamel D, Lane D, Vähäkangas $\mathrm{K}$. Comparative analysis of $\mathrm{p} 53$ protein immunoreactivity in prostatic, lung and breast carcinomas. Virchows Arch A Pathol Anat Histopathol 1992;421:223-8.

15 Park JG, Lee SK, Hong IG, Kim HS, Choe KJ, Kim WH, al. MDR1 gene expression: its effect on drug resistance to doxorubicin in human hepatocellular carcinoma cell lines. 7 Natl Cancer Inst 1994;86:700-5.

16 Chin K-V, Ueda K, Pastan I, Gottesmann MM. Modulation of activity of the promoter of the human MDR1 gene by of activity of the promoter of the hum

17 De Angelis P, Stokke T, Smedshammer L, Lothe RA, Lehne G, Chen Y, Clausen OPF. P-glycoprotein is not expressed in a majority of colorectal carcinomas and is not regulated by mutant p53 in vivo. Br f Cancer 1995;72:307-11. 